\title{
A Dynamic View of Protein Phosphatase 1 Interaction with its Inhibitors
}

\section{Sudhish Mishra ${ }^{1}$, Mandal A $^{2}$, Gupta RC ${ }^{1}$ and Mandal PK ${ }^{2 \star}$}

${ }^{1}$ Translational Science and Molecular Medicine, Michigan State University, Grand Rapids, MI 48202, USA

${ }^{2}$ Edward Waters College, Biology Program, Jacksonville, FL 32209, USA

\begin{abstract}
Protein phosphatase 1 (PP1) is well known for their role in signal transduction and protein function. Together with its inhibitors 1 and 2, it regulates wide variety of cellular activities. We have amplified catalytic subunit of PP1 (PP1c) and its inhibitors 1 (I-1) and 2 (I-2) from dog cardiac mRNA by rt-PCR and cloned into bacterial expression vector pCRT7. Cloned genes were expressed in E. coli BL21 (DE3) pLysS by IPTG induction. Functional positive clones were identified by western blotting of bacterial lysate and polymerase chain reaction. Double transformed bacterial cells were also generated by transforming PP1c clone with either I-1 or I-2. Activity of PP1 was analyzed in whole bacterial Iysate by measuring dephosphorylation of phos $\mathrm{b}$. Activities of inhibitors were analyzed by their capability to inhibit PP1 from dephosphorylation of phos $\mathrm{b}$. Our findings indicate differential regulation of PP1 by I-1 and I-2. Both expressed recombinant inhibitors 1 and 2 have high potency for inhibition of PP1 activity. Interestingly, I-2 co-expression caused increase in PP1c expression but no change in expression was observed when co-expressed with I-1.
\end{abstract}

Keywords: Protein phosphatase; Inhibitor; Gene expression; Cloning

\section{Introduction}

A well-controlled regulation of protein phosphatase and protein kinase is required to maintain the phosphorylation status of proteins. These proteins are responsible for modulating metabolic pathways as per their phosphorylation state. There are at least 4 types of serthr protein phosphatases, protein phosphatasel (PP1), protein phosphatase 2A (PP2A), protein phosphatase 2B (PP2B (Calcineurin) and protein phosphatase $2 \mathrm{C}$ (PP2C), which along with multiple types of protein kinases regulate phosphorylation status of metabolically active proteins. Protein phosphatase-1 (PP1) is a major ser-thr phosphatase which comprises of a catalytic subunit and a variable regulatory subunit. Catalytic subunit is a functional unit which is directed to subcellular compartments on the basis of binding to regulatory subunit [1]. PP1 can modulate various functions like, neuronal signaling, muscle contraction, protein synthesis, glycogen metabolism, cell cycle etc. [2]. PP1 has 3 specific heat stable inhibitors-inhibitor-1, inhibitor-2, inhibitor-3 and DARPP-2. Inhibitor-1 and DARPP-2 are phosphorylation dependent and requires phosphorylation by PKA at Thr-35 and Thr-34, respectively. Inhibitor-2 does not need phosphorylation to inhibit PP1 activity. Instead, calcium channel mediated phosphorylation of Ser-43 of Inhibitor- 2 relieves PP1 from its inhibition [3].

PP1 mediated phosphorylation state of many proteins are known to altered in pathological conditions including Heart failure where increased PP1 expression [4,5] caused cardiac dilation and premature death [6]. Limited gene manipulation studies with I-1 have shown promising results in normalizing cardiac function [7].

In view of these facts, a clear understanding of PP1 interactions with its inhibitors is required. We do not have enough information available about interaction of PP1 and its inhibitors and detailed knowledge will provide the information to manipulate metabolic pathways for treatment of wide spectrum of diseases wherever PP1 is involved.

In the current study, we have cloned the genes of PP1, inhibitor-1 and inhibitor-2 and expressed them in BL21 (DE3) cells by Isopropyl-D thiogalactoside (IPTG) induction. We analyzed the activity of PP1 and compared the inhibition of PP1 by inhibitor- 1 and inhibitor- 2 . Since both inhibitors are potent inhibitors of PP1, they can be used as therapeutic agents in diseases where activity of PP1 is enhanced.

\section{Materials and Methods}

\section{Materials}

Cloning vector pcrT7-topo and bacterial expression system consist of E. coli BL21 (DE3) pLysS cells, mini plasmid isolation kit, IPTG and ampicillin were purchased from Invitrogen. Agar and LB media was from Bio 101 Systems (QBiogene, Carlsbad, CA).

\section{Cloning of PP1, inhibitor-1 and Inhibitor-2}

Using custom primers (Table 1), cDNA from dog heart, was amplified by PCR and cloned in to pCR-T7-topo vector according to manufacturer's instruction (Gene Bank Accession Nos. AY062037, AY063765 and EU170432). The recombinant plasmid containing gene for PP1 and inhibitors were isolated and purified. Purified recombinant plasmids were used to transform E. coli BL21(DE3) pLysS cells for expression studies.

\section{Induction of gene expression}

The recombinant proteins were expressed in BL21 (DE3) cells by IPTG induction according to the instructions provided by supplier (Invitrogen). Briefly, fresh LB medium was inoculated by overnight culture of cloned PP1 or inhibitors transformed in BL21 (DE3) cells. After growing the cultures for 2 hours, IPTG was added up to $1 \mathrm{mM}$ of final concentration. Cultures were further allowed to grow up to desired time ( $\sim 4 \mathrm{hrs}$.). Bacterial cells were harvested by centrifugation and resuspended in $50 \mathrm{mM}$ Tris- $\mathrm{HCl}$ (pH 7.4), $0.5 \mathrm{mM}$ sodium EDTA ( $\mathrm{pH}$ 7.0), $0.3 \mathrm{M}$ sucrose, and protease inhibitors ( $0.8 \mathrm{mM}$ benzamidine, $0.8 \mathrm{mg} / \mathrm{l}$ each aprotinin and leupeptin, and $0.4 \mathrm{~g} / \mathrm{l}$ antipain).

\section{PP1 activity Assay}

Bacterial lysate was prepared by homogenization in the same

*Corresponding author: Prabir K Mandal, Professor, Biology Program, Edward Waters College, USA, Tel: 904-470-8091; E-mail: prabir.mandal0807@ewc.edu

Received April 13, 2015; Accepted April 24, 2015; Published April 29, 2015

Citation: Mishra S, Mandal A, Gupta RC, Mandal PK (2015) A Dynamic View of Protein Phosphatase 1 Interaction with its Inhibitors. J Bioprocess Biotech 5: 221 doi:10.4172/2155-9821.1000221

Copyright: $\odot 2015$ Mishra S, et al. This is an open-access article distributed under the terms of the Creative Commons Attribution License, which permits unrestricted use, distribution, and reproduction in any medium, provided the original author and source are credited. 


\begin{tabular}{|c|c|c|}
\hline Gene & Sequence & Size (bp) \\
\hline \multirow{3}{*}{ Inhibitor-1 } & 5'-CCCAAAAgTgAAggAATAAgAA-3' & \multirow{2}{*}{602} \\
\hline \multirow{3}{*}{ Inhibitor-2 } & 5'-CCAATggCggCCTCgACggCCTC-3' & \\
\cline { 2 - 2 } & 5'-TgAAgAACAAgAAgCAACgTACTA-3' & \multirow{2}{*}{697} \\
\hline \multirow{2}{*}{ PP1c } & 5'-gCCATgTCCgACAgCgAgAAg-3' & \\
\cline { 2 - 3 } & 5'-TCCATgTTCCCCgTgACAggTg-3' & 1122 \\
\hline
\end{tabular}

Table 1: Primers used for polymerase chain reaction and sizes of amplified products.

buffer it was resuspended (Tris-sucrose buffer). With the use of $\left[{ }^{32} \mathrm{P}\right]$ phosphorylase $b$ as the substrate, PP activity was determined in the bacterial lysate. The assay was performed in a $60 \mu \mathrm{l}$ aliquot that consisted of $50 \mathrm{mM}$ Tris- $\mathrm{HCl}$ (pH 7.4), $5 \mathrm{mM}$ caffeine, $0.5 \mathrm{mM}$ EGTA, $0.5 \mathrm{mM}$ EDTA, $50 \mathrm{mM} \beta$-mercaptoethanol $100 \mathrm{ng}$ of aprotinin (protease inhibitor), $1 \mu \mathrm{g}$ of the cell lysate and $550 \mathrm{pmol}{ }^{32} \mathrm{P}$-phosphorylase $a$. The assay was initiated by adding the phos a mix and carried out for $10 \mathrm{~min}$ at $34^{\circ} \mathrm{C}$. Incubation was rapidly stopped by addition of $20 \mu \mathrm{l}$ of $60 \%$ TCA and $20 \mu \mathrm{l}$ of BSA (50 mg/ml). Tubes were held in ice for 10 $\mathrm{min}$ and then centrifuged at 12,000 $\mathrm{g}$ for $5 \mathrm{~min}$. After centrifugation, ${ }^{32} \mathrm{P}$ radioactivity was counted in $80 \mu \mathrm{l}$ of clear supernatant in $5 \mathrm{ml}$ of liquid scintillation fluid. PP1 activity was calculated by comparing with samples with no IPTG induction. Activity in each sample was expressed as $\mathrm{pmol}{ }^{32} \mathrm{P}$ released $/ \mathrm{min} / \mathrm{mg}$ of protein.

\section{Inhibitor activity assay}

Activity of inhibitor- 1 and inhibitor- 2 was measured by mixing bacterial lysate of inhibitor expressions with lysate from PP1 expression before adding phos a mix to measure phosphatase activity. Briefly, 10 $\mu \mathrm{l}(1 \mu \mathrm{g})$ of PP1 and $30 \mu \mathrm{l}(15 \mu \mathrm{g}$ or $30 \mu \mathrm{g})$ of inhibitor-1 or inhibitor-2 was mixed in the assay tube and kept in ice for $5 \mathrm{~min}$. Reaction was initiated by adding $20 \mu \mathrm{l}$ phos a mix and was incubated at $34^{\circ} \mathrm{C}$ for $10 \mathrm{~min}$. Reaction was terminated by adding $20 \mu \mathrm{l}$ of $60 \%$ TCA and 20 $\mu \mathrm{l}$ of BSA $(50 \mathrm{mg} / \mathrm{ml})$. Inhibitor activity was calculated by comparing released ${ }^{32} \mathrm{P}$ with the samples without inhibitor.

\section{Western blotting}

To determine the protein expression of PP1C, Inhibitor-1 and inhibitor-2, western blotting was performed on SDS extracts of the bacterial extracts. Bacterial culture was centrifuged at $6000 \mathrm{rpm}$ for 15 min. Pellet was resuspended in Tris-Sucrose homogenization buffer and homogenized for $2 \times 15 \mathrm{sec}$ using homogenizer. Extract was prepared by adding $1 / 10^{\text {th }}$ volume of $20 \%$ SDS in the homogenized sample followed by incubating in boiling water for $10 \mathrm{~min}$. After boiling samples were allowed to cool at room temperature and centrifuged at $12,000 \times \mathrm{g}$ for $15 \mathrm{~min}$. Supernatant was collected in the fresh tubes and used for western blotting. Protein amount was measured according to Lowery's method [8]. Equal amount of protein was subjected to electrophoresis on 4-20\% SDS-polyacrylamide gel (Bio$\mathrm{Rad})$, and the separated proteins were electrophoretically transferred to a nitrocellulose membrane $[9,10]$. Accuracy of the electro transfer was confirmed by staining the membrane with $0.1 \%$ ponceau $S$. For the immunoreaction, the nitrocellulose blot was incubated with diluted primary antibody (monoclonal or polyclonal) based on the supplier's instructions. Antibody-binding protein was visualized by autoradiography after treating the blot with horseradish peroxidaseconjugated secondary antibody (anti-mouse for PP1 and Inhibitor-2 and anti-rabbit for inhibitor-1) and enhanced chemiluminescence color-developing reagents according to the supplier (NEN).

\section{Co-transformation of $E$. coli}

Clones of PP1c and inhibitors (either inhibitor-1 or inhibitor-2) were mixed in equal concentration of $5 \mathrm{ng} / \mu \mathrm{l}$. One $\mu \mathrm{l}$ of this mixture was added into chemically competent BL21 pLysS cells and transformed by heat shock at $42^{\circ} \mathrm{C}$. Transformed cells were selected on amp-LB agar plate. 10 colonies were grown in $10 \mathrm{ml}$ culture and induced by IPTG for gene expression. Dual-positive clones were selected by western blot analysis for PP1 and inhibitor-2. Phosphatase activity and western blots were carried out on these samples according to the methods described in previous sections.

\section{Results}

\section{Expression of recombinant proteins}

To analyze the expression of recombinant PP1, culture was incubated for different time points ( $1 \mathrm{hr}-4 \mathrm{hrs}$ ) after induction with 0.5 mM IPTG. Both western blot and activity shows increasing trend with time (Figure 1). Similarly, cultures for inhibitor-1 and inhibitor- 2 were incubated for 1-4 hrs. after adding $1 \mathrm{mM}$ IPTG. Increase in time of expression after induction with $1 \mathrm{mM}$ IPTG showed increasing trend in expression and PP1 inhibiting activity for both I-1 and I-2 (Figures 2 and 3 ).

\section{Effect of heat on inhibitor-1 and inhibitor-2}

Naturally both of these inhibitors are heat and acid stable. We tested expressed inhibitor-1 and inhibitor-2 for heat resistance. After treatment both inhibitors not only maintained their activity but also showed $10-20 \%$ enhancement in their activity (Figure 4 ).

\section{Effect of co-expression}

I- 1 and I-2 were separately co-expressed with PP1c inside single bacterium to study their effect on each other. I-1 co-expression had no effect on amount of gene expression of PP1 or vice versa but I-2 coexpression with PP1c resulted in higher expression of both genes when compared to their individual expression (Figures 5 and 6).

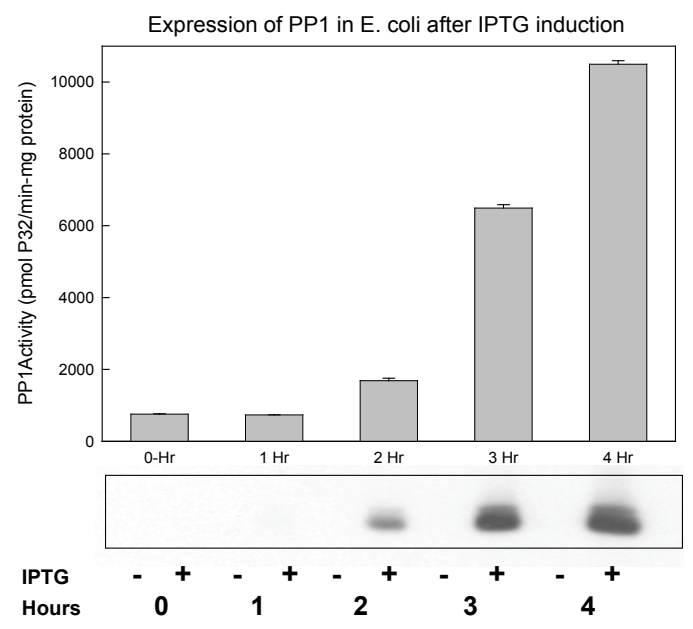

Figure 1: Gene expression at different time intervals after induction with $0.5 \mathrm{mM}$ IPTG. A: PP1 activity in bacterial homogenate and B: western blot of PP1c in uninduced and induced samples. 

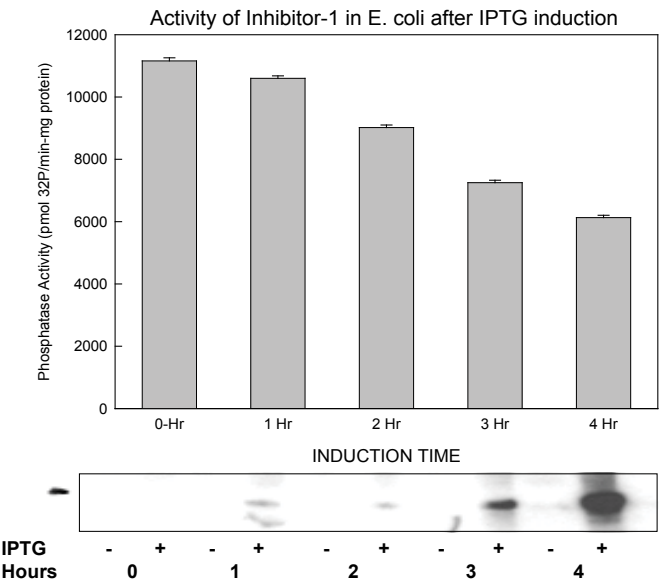

Figure 2: Gene expression at different time intervals after induction with 1.0 mM IPTG. A: PP1 activity in bacterial homogenate and B: western blot of I-1 in un-induced and induced samples.

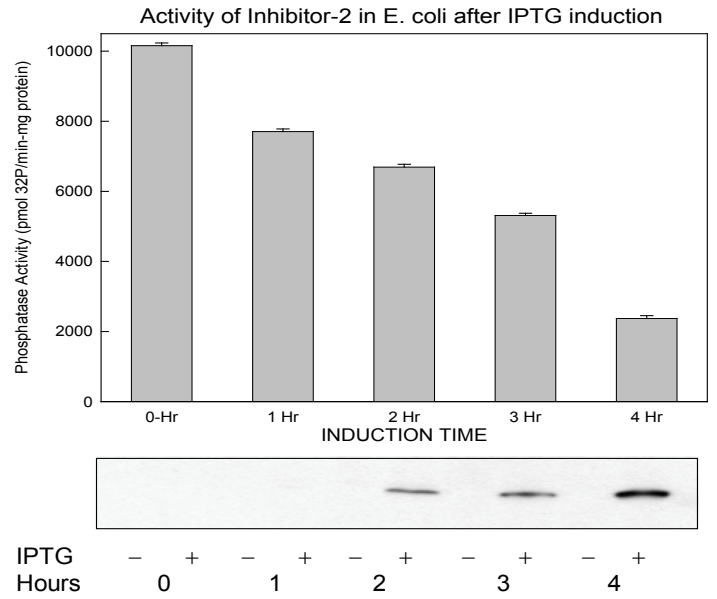

Figure 3: Gene expression at different time intervals after induction with 1.0 mM IPTG. A: PP1 activity in bacterial homogenate and B: western blot of I-2 in un-induced and induced samples.

\section{Discussion}

We have cloned and analyzed the expression of canine PP1 and inhibitors in bacterial system. The purpose of study was to characterize these genes for future gene manipulation studies. Our bacterial expression system utilizes T7 promoter which results in robust expression of mammalian genes in bacteria. We used BL21(DE3) pLysS cells for expression of canine PP1 and inhibitors genes. These cells maintain T7 RNA polymerase under suppressed conditions to minimize basal level expression. An inducer IPTG is required to relieve T7 RNA polymerase from suppression and start gene expression [11]. We analyzed the amount and activity of expressed products up to 4 hours after addition of IPTG. Samples were collected for analysis after each hour. Our results showed that gene expression is associated with time of incubation after addition of IPTG. PP1 and both inhibitors continuously increased up to $4 \mathrm{hrs}$. It indicates that the products are stable and active at least up to 4 hrs. and they can be used for further analysis.
Analysis of gene function showed maximum PP1 activity in extract of $0.5 \mathrm{mM}$ IPTG induced cells in comparison to extracts prepared after incubation with other concentrations of IPTG (data not shown), thus this concentration of IPTG was used for further experiments. The decrease in activity at higher concentrations of IPTG may be due to aggregation of enzyme at very high concentrations [12,13]. Maximum activity of both inhibitors were observed at $1 \mathrm{mM}$ IPTG concentration (data not shown), thus selected for further experiments.

In the earlier studies several workers have reported about dependence of PP1 on $\mathrm{Mn}^{2+}$ [14]. There are other reports also that $\mathrm{Mn}^{2+}$ is required for activation of PP1 [15]. The role of $\mathrm{Mn}^{2+}$ in activation of PP1 is not clear. However, the PP1 described in this manuscript is $\mathrm{Mn}^{2+}$ independent.

PP1 inhibitors $1 \& 2$ are acid and heat stable and mostly exist in random coil structure [16-19]. This unique structure makes them resistant to heat but sensitive to proteases. Inhibitors acquire flexible conformation and they bind to PP1 at multiple sites with a long range distribution on the surface of the enzyme [20]. We tested the PP1 inhibition activity of both inhibitors after heat treatment and observed slight increase in PP1 inhibition after treatment. This increase in inhibition may be due to heat-induced dissociation of some interacting proteins from inhibitors. This separation might make them free and available to interact with PP1.

Co-expression of Inhibitors with PP1c gives an opportunity to study their interaction. Selective increased expression of both genes during co-expression of I-2 and PP1c indicates their unique interaction which needs to be explored. It looks like that inhibition of PP1 activity by inhibitor-2 somehow inducing more expression of PP1. This extra PP1 requires extra inhibitor-2, which induces expression of more inhibitor-2. This feedback mechanism may be the cause of increased

A

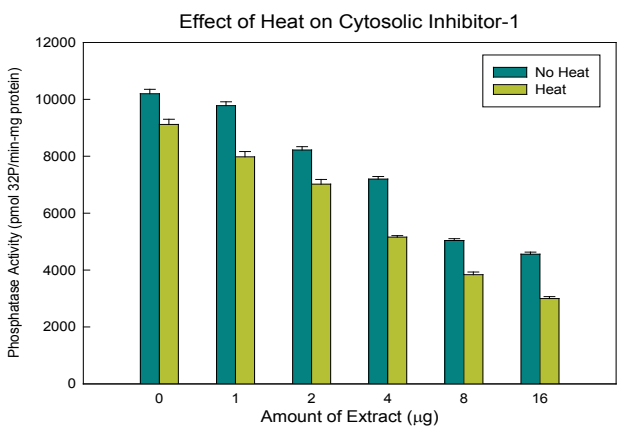

B

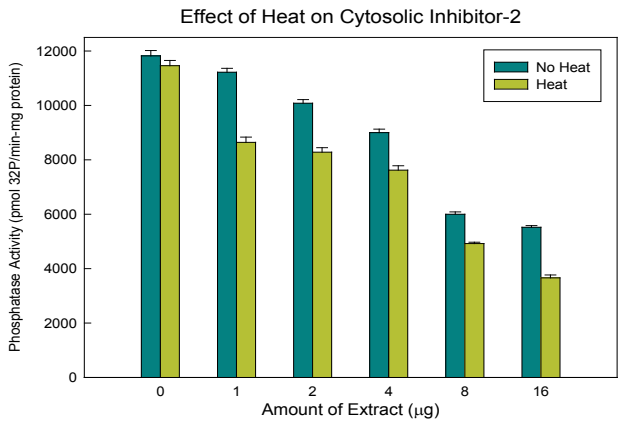

Figure 4: Effect of Heat on inhibitors. Inhibition of phosphatase activity by different amount of I-1 (A) and I-2 (B) induced bacterial extract. 
Citation: Mishra S, Mandal A, Gupta RC, Mandal PK (2015) A Dynamic View of Protein Phosphatase 1 Interaction with its Inhibitors. J Bioprocess Biotech 5: 221 doi:10.4172/2155-9821.1000221

Effect of Inhibitor-1 co-expression on Phosphatase
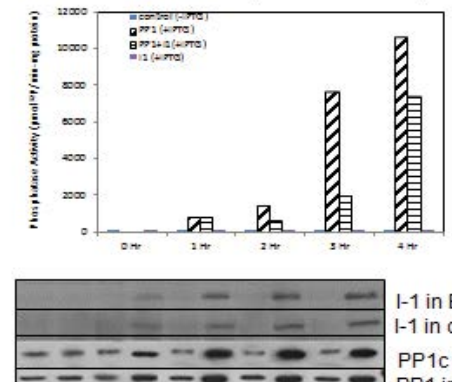

$1-1$ in BL21

I-1 in co-transformed BL21

PP1c in BL21

PP1 in co-transformed BL21

Figure 5: Co-expression of PP1 and inhibitor-2. Top: Phosphatase activity in the IPTG induced bacterial extracts that contains genes for PP1 alone, PP1 and $\mathrm{I}-1$ both and $\mathrm{I}-1$ alone. Control samples are bacterial extracts without IPTG induction. Bottom: Western blot analysis in IPTG induced bacterial extracts: For I-1 in only I-1 containing bacteria and in co-transfected bacteria; For PP1 in only PP1 containing bacteria and co-transfected bacteria.

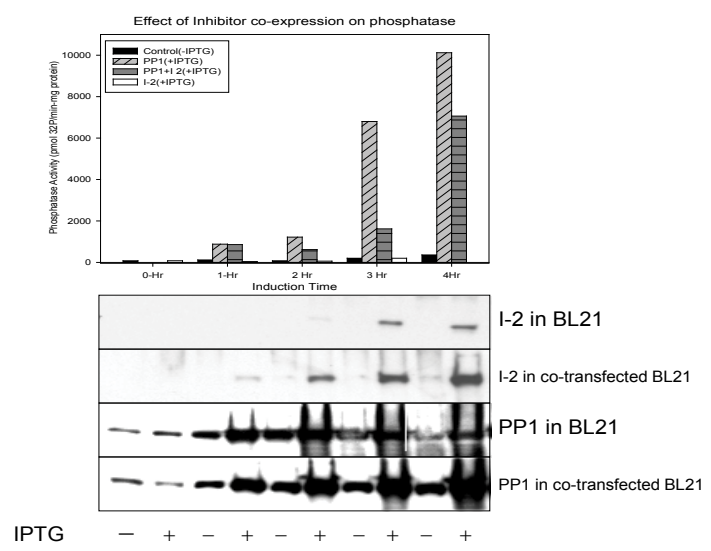

Figure 6: Co-expression of PP1 and inhibitor-2. Top: Phosphatase activity in the IPTG induced bacterial extracts that contains genes for PP1 alone, PP1 and I-2 both and I-2 alone. Control samples are bacterial extracts without IPTG induction. Bottom: Western blot analysis in IPTG induced bacterial extracts: For $\mathrm{I}-2$ in only I-2 containing bacteria and in co-transfected bacteria; For PP1 in only PP1 containing bacteria and co-transfected bacteria.

expression of both genes. In our earlier study on one kidney one-clip model of hypertension, we have reported increased expression of PP1 and Inhibitor-2 [21]. This may be due to feedback mechanism proposed in the current study. One recent study on PPI-I2 complex analysis by X-ray crystallography has shown that Thr-74 phosphorylation of I-2 activates PP1 by dissociates it from metal containing active site of PP1 [22] but how they affect gene expression is not known.

In summary, phosphatase inhibition by I-1 and I-2 are very well known for long time. A detailed study about their interactions, effect on associated proteins and their role on gene expression is required. A better understanding of phosphatase-inhibitor relationship will help in better manipulation of metabolic pathways.

\section{References}

1. Cohen PT (2002) Protein phosphatase 1--targeted in many directions. J Cell Sci 115: 241-256.

2. Shenolikar S (1994) Protein serine/threonine phosphatases--new avenues for cell regulation. Annu Rev Cell Biol 10: 55-86.

3. Siddoway BA, Altimimi HF, Hou H, Petralia RS, Xu B, et al. (2013) An essential role for inhibitor-2 regulation of protein phosphatase-1 in synaptic scaling. $J$ Neurosci 33: 11206-11211.

4. Mishra S, Gupta RC, Tiwari N, Sharov VG, Sabbah HN (2002) Molecula mechanisms of reduced sarcoplasmic reticulum $\mathrm{Ca}(2+)$ uptake in human failing left ventricular myocardium. J Heart Lung Transplant 21: 366-373.

5. Netticadan T, Temsah RM, Kawabata K, Dhalla NS (2000) Sarcoplasmic reticulum $\mathrm{Ca}(2+) / C$ almodulin-dependent protein kinase is altered in heart failure. Circ Res 86: 596-605.

6. Carr AN, Schmidt AG, Suzuki Y, del Monte F, Sato Y, et al. (2002) Type 1 phosphatase, a negative regulator of cardiac function. Mol Cell Biol 22: 4124 4135.

7. Pritchard TJ, Kawase Y, Haghighi K, Anjak A, Cai W, et al. (2013) Active inhibitor-1 maintains protein hyper-phosphorylation in aging hearts and halts remodeling in failing hearts. PLoS One 8: e80717.

8. Laemmli UK (1970) Cleavage of structural proteins during the assembly of the head of bacteriophage T4. Nature 227: 680-685

9. Gupta RC, Mishra S, Mishima T, Goldstein S, Sabbah HN (1999) Reduced sarcoplasmic reticulum $\mathrm{Ca}(2+)$-uptake and expression of phospholamban in left ventricular myocardium of dogs with heart failure. J Mol Cell Cardiol 31 1381-1389.

10. Gupta RC, Shimoyama H, Tanimura M, Nair R, Lesch M, et al. (1997) SR $\mathrm{Ca}(2+)$-ATPase activity and expression in ventricular myocardium of dogs with heart failure. Am J Physiol 273: H12-18.

11. Alexander WA, Moss B, Fuerst TR (1992) Regulated expression of foreign genes in vaccinia virus under the control of bacteriophage T7 RNA polymerase and the Escherichia coli lac repressor. J Virol 66: 2934-2942.

12. Zhang AJ, Bai G, Deans-Zirattu S, Browner MF, Lee EY (1992) Expression of the catalytic subunit of phosphorylase phosphatase (protein phosphatase-1) in Escherichia coli. J Biol Chem 267: 1484-1490.

13. Zhuo S, Clemens JC, Hakes DJ, Barford D, Dixon JE (1993) Expression purification, crystallization, and biochemical characterization of a recombinant protein phosphatase. J Biol Chem 268: 17754-17761.

14. Silberman SR, Speth M, Nemani R, Ganapathi MK, Dombradi V, et al. (1984) Isolation and characterization of rabbit skeletal muscle protein phosphatases C-I and C-II. J Biol Chem 259: 2913-2922.

15. Brautigan DL, Ballou LM, Fischer EH (1982) Activation of skeletal muscle phosphorylase phosphatase. Effects of proteolysis and divalent cations. Biochemistry 21: 1977-1982.

16. Huang HB, Chen YC, Lee TT, Huang YC, Liu HT, et al. (2007) Structural and biochemical characterization of inhibitor-1alpha. Proteins 68: 779-788.

17. Herzig S, Neumann J (2000) Effects of serine/threonine protein phosphatases on ion channels in excitable membranes. Physiol Rev 80: 173-210.

18. Chyan CL, Tang TC, Chen Y, Liu H, Lin FM, et al. (2001) Letter to the editor: backbone $1 \mathrm{H}, 15 \mathrm{~N}$, and $13 \mathrm{C}$ resonance assignments of inhibitor-1--a protein inhibitor of protein phosphatase-1. J Biomol NMR 21: 287-288.

19. Huang HB, Chen YC, Tsai LH, Wang H, Lin FM, et al. (2000) Backbone 1H $15 \mathrm{~N}$, and $13 \mathrm{C}$ resonance assignments of inhibitor-2 -- a protein inhibitor of protein phosphatase-1. J Biomol NMR 17: 359-360.

20. Egloff MP, Johnson DF, Moorhead G, Cohen PT, Cohen P, et al. (1997) Structural basis for the recognition of regulatory subunits by the catalytic subunit of protein phosphatase 1. EMBO J 16: 1876-1887.

21. Gupta RC, Mishra S, Yang XP, Sabbah HN (2005) Reduced inhibitor 1 and 2 activity is associated with increased protein phosphatase type 1 activity in left ventricular myocardium of one-kidney, one-clip hypertensive rats. Mol Cell Biochem 269: 49-57.

22. Cannon JF (2013) How phosphorylation activates the protein phosphatase-1 inhibitor-2 complex. Biochim Biophys Acta 1834: 71-86. 